\title{
Microsatellite DNA instability and loss of heterozygosity in bronchial asthma
}

\author{
E. Paraskakis, G. Sourvinos, F. Passam, N. Tzanakis, E.G. Tzortzaki, M. Zervou, D. Spandidos, \\ N.M. Siafakas
}

Microsatellite DNA instability and loss of heterozygosity in bronchial asthma. E. Paraskakis, G. Sourvinos, F. Passam, N. Tzanakis, E.G. Tzortzaki, M. Zervou, D. Spandidos, N.M. Siafakas. (C) ERS Journals Ltd 2003.

ABSTRACT: Genetic alterations, such as loss of heterozygosity (LOH) or microsatellite instability (MI), have been reported in both malignant and benign disorders. In order to identify loci of deoxyribonucleic acid (DNA) mutation in asthma, MI and LOH were studied in sputum cells.

DNA was extracted from cells in the sputum and blood cells of 22 patients with moderate asthma. Cells were analysed for $\mathrm{MI}$ and $\mathrm{LOH}$ using 18 polymorphic markers on chromosome 5q, 6p, 11q, 14q. Microsatellite analysis was also performed in six healthy subjects.

None of the healthy individuals exhibited any genetic alteration. Genetic alterations were found in 16 of 22 asthmatic patients $(73 \%)$. In total, $12(54.5 \%)$ patients exhibited LOH only, one (4.5\%) MI only, while three showed both MI and LOH. The highest incidence of $\mathrm{LOH}$ and MI was found on chromosome 14q. Mean immunoglobulin $\mathrm{E}$ and blood eosinophil levels were significantly higher in asthmatics with three or more genetic alterations.

A high incidence of genetic alterations in the deoxyribonucleic acid of the sputum cells was found in asthmatic patients. Further studies are needed to identify the role of loss of heterozygosity and microsatellite instability in the investigation of genetic susceptibility of asthma and thus, in its pathogenesis.

Eur Respir J 2003; 22: 951-955.
Dept of Thoracic Medicine and Laboratory of Virology, Medical School, University of Crete, Greece.

Correspondence: N.M. Siafakas

Dept of Thoracic Medicine

University General Hospital

71110 Heraklion

Crete

Greece

Fax: 302810542650

E-mail: siafak@med.uoc.gr

Keywords: Atopy

deoxyribonucleic acid alterations

genetic susceptibility

human genome

hyperresponsiveness

induced sputum

Received: January 302003

Accepted after revision: July 142003
Asthma is a chronic inflammatory disorder of the airways in which many cell types play a role, in particular mast cells, eosinophils, T-lymphocytes, neutrophils and epithelial cells [1]. In addition to inflammation, the airway walls of asthmatic patients are characterised by a number of structural alterations that lead in severe cases to abnormal "remodeling" and permanently reduced airway caliber [2-6]. The inheritance of asthma has been shown to be complex, characterised by polygenic inheritance and genetic heterogenicity [7]. Recently, it has become apparent that several regions in chromosomes $5 q, 6 p, 11 q$, and $14 q$ of the genome are likely to contain susceptibility genes for asthma [8-13]. These regions harbour genes for the following: 1) T-helper cell type 2 cytokines (interleukin (IL)-4, IL-5, IL-9); 2) major histocompatability complex molecules and tumour necrosis factor- $\alpha$; 3) $\beta$-chain of the high affinity immunoglobulin $\mathrm{E}$ (IgE) (Fc\&RI $\beta$ ); and 4) T-cell receptors, which are involved in the inflammation procedure $[5,6,14,15]$. The mediators or receptors encoded in those sites are associated with allergy and bronchial hyperresponsiveness, contributing to elevated levels of IgE and eosinophilic count [5-9, 14]. Lately, efforts have been concentrated on mapping these chromosome regions and assessing the role of these genes in the pathogenesis of asthma.

Deoxyribonucleic acid (DNA) microsatellites are highly polymorphic markers used to map specific areas of chromosomes. Certain genetic alterations in microsatellite markers, including microsatellite loss of heterozygosity ( $\mathrm{LOH})$ and microsatellite instability (MI), have been reported in a number of human malignancies [16-19]. LOH and MI have recently also been detected in benign diseases characterised by abnormal accumulation of normal cells, such as actinic keratosis [20, 21], pterygium [22, 23], and atherosclerosis [24]. In addition, MI and LOH have been detected in chronic obstructive pulmonary disease (COPD) [25], sarcoidosis [26] and idiopathic pulmonary fibrosis [27].

The aim of the study was to detect chromosomal regions with DNA deteriorates correlated with asthma pathogenesis using as genetic screening tools the MI and LOH. In total, 18 highly polymorphic microsatellite markers located on chromosomes $5 \mathrm{q}, 6 \mathrm{p}, 11 \mathrm{q}$, and $14 \mathrm{q}$ were investigated. The results of the study showed that these genetic alterations are detectable phenomena in the above regions of the genome in asthmatic patients and thus, those loci with high mutation rates deserve further investigation.

\section{Subjects and methods}

\section{Subjects}

A total of 22 asthmatic patients, aged 18-65 yrs, were studied. The inclusion criteria were: 1) lifelong nonsmokers with history of asthma for $\geqslant 1 \mathrm{yr}$, developed before aged $45 \mathrm{yrs}$; 2) either an increase of forced expiratory volume in one second $\geqslant 12 \%$ predicted after inhalation of four puffs of $100 \mu \mathrm{g}$ salbutamol, or a median daily variation in peak 
expiratory flow rate $\geqslant 15 \%$ for $\geqslant 4$ days a week for at least the previous 2 weeks.

All patients were treated with inhaled corticosteroids daily, with a dose of $1000-1600 \mu \mathrm{g}$ beclomethasone or budesonide, or 500-800 $\mu \mathrm{g}$ fluticazone, for $\geqslant 1 \mathrm{yr}$ before the study.

Exclusion criteria were as follows: 1) patients with active lung disease other than asthma; 2) patients with a history of cancer; 3) pregnant women; 4) patients receiving immunosuppressive medications other than inhaled corticosteroids; 5) patients receiving chronic oxygen therapy; and 6) patients with mental retardation.

The control group consisted of six healthy, nonasthmatic, nonatopic, never-smoked subjects receiving no medication. All subjects underwent spirometry and blood tests for total IgE and eosinophilic counts (table 1).

\section{Methods}

Sputum and peripheral blood specimens were collected from all subjects. The sputum sample was obtained by sputum induction, a safe, noninvasive method [28]. A solution of gradually increasing $\mathrm{NaCl}$ concentration was inhaled through an ultrasound nebuliser (Ultraneb 2000; DeVilbiss Healthcare Inc. Somerset, PA, USA) until an adequate quantity of sample was taken. The viscid portion of the expectorated sample was separated from the sputum as described previously [29]. Spirometric evaluation of airflow limitation was performed before and during this procedure according to standard protocols [29]. No severe adverse reactions were noticed during this study. Sputum samples with cell viability $>90 \%$ and epithelial cell contamination $<2 \%$ were used for DNA extraction. Blood and sputum specimens were stored at $-70^{\circ} \mathrm{C}$ for DNA extraction.

Deoxyribonucleic acid extraction. DNA from sputum cytological material was extracted by the standard boiling and ethanol precipitation method. The peripheral blood cell DNA was extracted with the Nucleon Kit (Amersham Biosciences Corp, NJ, USA) following the manufacturer's instructions. DNA samples were stored at $4^{\circ} \mathrm{C}$.

Microsatellite marker microsatellite instability and loss of heterozygosity analysis. Eighteen polymorphic microsatellite markers located on chromosomes $5 \mathrm{q}, 6 \mathrm{p}, 11 \mathrm{q}$, and 14q were used to reveal MI or LOH. The selection of these chromosomal regions was based on previous knowledge that these regions contain genes of cytokines, mediators or receptors postulated to be candidate genes for atopy and asthma [7-13]. The

Table 1.-Mean anthropometrical, immunological and spirometrical characteristics of the subjects

\begin{tabular}{lcc}
\hline & Asthmatics & Controls \\
\hline Subjects n & 22 & 6 \\
Female/male & $15 / 7$ & $3 / 3$ \\
Age yrs & $46.73 \pm 15$ & $36.33 \pm 4.76$ \\
IgE IU·mL $\mathrm{mL}^{-1}$ & $207.84 \pm 218.21$ & $38 \pm 25.09^{*}$ \\
Blood eosinophil cells $\cdot \mu \mathrm{L}^{-1}$ & $332.6 \pm 280.68$ & $37.33 \pm 34.89^{*}$ \\
FEV1 L & $2.01 \pm 0.89$ & $5.33 \pm 1.59$ \\
FVC L & $3.1 \pm 1.16$ & $5.86 \pm 1.73$ \\
FEV1 \% pred & $75 \pm 26.5$ & $141.5 \pm 20.53^{*}$ \\
FVC \% pred & $88 \pm 23.67$ & $132.33 \pm 17.09^{*}$ \\
FEV1/FVC & $69.66 \pm 12.5$ & $90.8 \pm 1.57^{*}$ \\
\hline
\end{tabular}

Data are presented as mean \pm SD unless otherwise stated. IgE: immunoglobulin E; FEV1: forced expiratory volume in one second; FVC: forced vital capacity; $\%$ pred: $\%$ predicted. $*$ : $p<0.05$ between asthmatics versus controls. microsatellite markers used in both groups were: D5S207, D5S376, D5S82, D6S1002, D6S2223, D6S429, D6S259, D6S263, D11S2072, D11S480, D11S1253, D11S1383, D11S1876, D14S258, D14S251, D14S72, D14S292, and D14S588 (table 2).

The polymerase chain reaction (PCR) technique was used to amplify DNA sequences. PCRs were performed in $50 \mathrm{Ml}$ of $10 \times$ buffer $(670 \mathrm{mM}$ Tris HCL, pH $8.5 ; 166 \mathrm{mM}$ ammonium sulfate; $67 \mathrm{mM}$ magnesium chloride; $1.7 \mathrm{mg} \cdot \mathrm{mL}^{-1}$ bovine serum albumin; $100 \mu \mathrm{M} \beta$-mercaptoethanol and $1 \%$ (weight by volume) octoxynol-9 (Triton X-100) and $1 \mathrm{U}$ of Taq DNA polymerase (Gibco/BRL Life Technologies Inc, Gaithersburg, MD, USA)). Reactions were denatured for $5 \mathrm{~min}$ at $95^{\circ} \mathrm{C}$ and the DNA was subsequently amplified for 30 cycles at $95^{\circ} \mathrm{C}$, $55^{\circ} \mathrm{C}$ and $72^{\circ} \mathrm{C}$ during each step. A volume of $10 \mu \mathrm{l}$ of the PCR product was analysed by electrophoresis in an $8 \%$ polyacrylamide gel, followed by silver staining. Gels were inspected to compare the intensity of staining for various alleles in similar amount of DNA from sputum and control (peripheral blood). Two scientists who were unaware of the clinical characteristics of the subjects performed independent readings [26]. In case of disagreement between the two investigators, PCR products were analysed in a $6 \%$ polyacrilamide 7 M Urea 1XTB sequencing gel (LICOR 2400 DNA Sequencer, Lincoln, NE, USA) and alleles were sized with GENEPROFILER software (SCANALYTICS, USA) for verification.

MI was scored by comparing the electrophoretic patterns of the microsatellite markers amplified from the paired DNA preparations (sputum/peripheral blood) and demonstrating a shift of one or both of the alleles in the sputum DNA specimens. The shift was indicated by an addition or deletion of one or more repeat units, resulting in the generation of novel microsatellite alleles. $\mathrm{LOH}$ was defined as a $\geqslant 50 \%$ reduction in the intensity of the pathologic allele (sputum), compared with the corresponding normal allele (peripheral blood) [19, 25-27].

Statistical analysis. Quantitative measurements between two groups were compared by an unpaired t-test and between three groups by analysis of variance test. The Chi-squared test was used for comparison of percentages. A p-value of $<0.05$ was considered statistically significant.

Ethics. The study was approved by Medical Research Ethics Committee of the hospital and patients gave their consent.

\section{Results}

None of the healthy control subjects exhibited any genetic alteration of the eighteen markers tested. Figure 1 shows typical examples of MI and LOH of various markers. The results of microsatellite analysis per marker and patient are shown in table 2.

In total, 16 of the 22 patients $(73 \%)$ showed genetic alteration in sputum cells at one or more of the microsatellite markers tested. LOH in one or more markers was found in 15 of 22 patients $(68 \%)$. Ten asthmatic patients $(50 \%)$ showed LOH in more than one marker (table 2). Four patients $(18 \%)$ exhibited MI at one or more marker. Three patients $(14 \%)$ displayed both MI and LOH (table 2). The maximum total number of alteration (LOH and MI) was seen in patient 17 (eight alterations).

The proportions of samples exhibiting $\mathrm{LOH}$ at markers on chromosomal regions 5q, 6p, 11q, and 14q were 6/22, 10/22, $7 / 22$, and $8 / 22$, respectively. The marker most frequently affected with either LOH or MI was D14S292 on chromosome 14q32.1-32.3, with six alterations, followed by D6S263 on $6 \mathrm{p} 23-24.2$, D6S2223 on 6p21.3, and D14S258 on 14q23-24.3, 


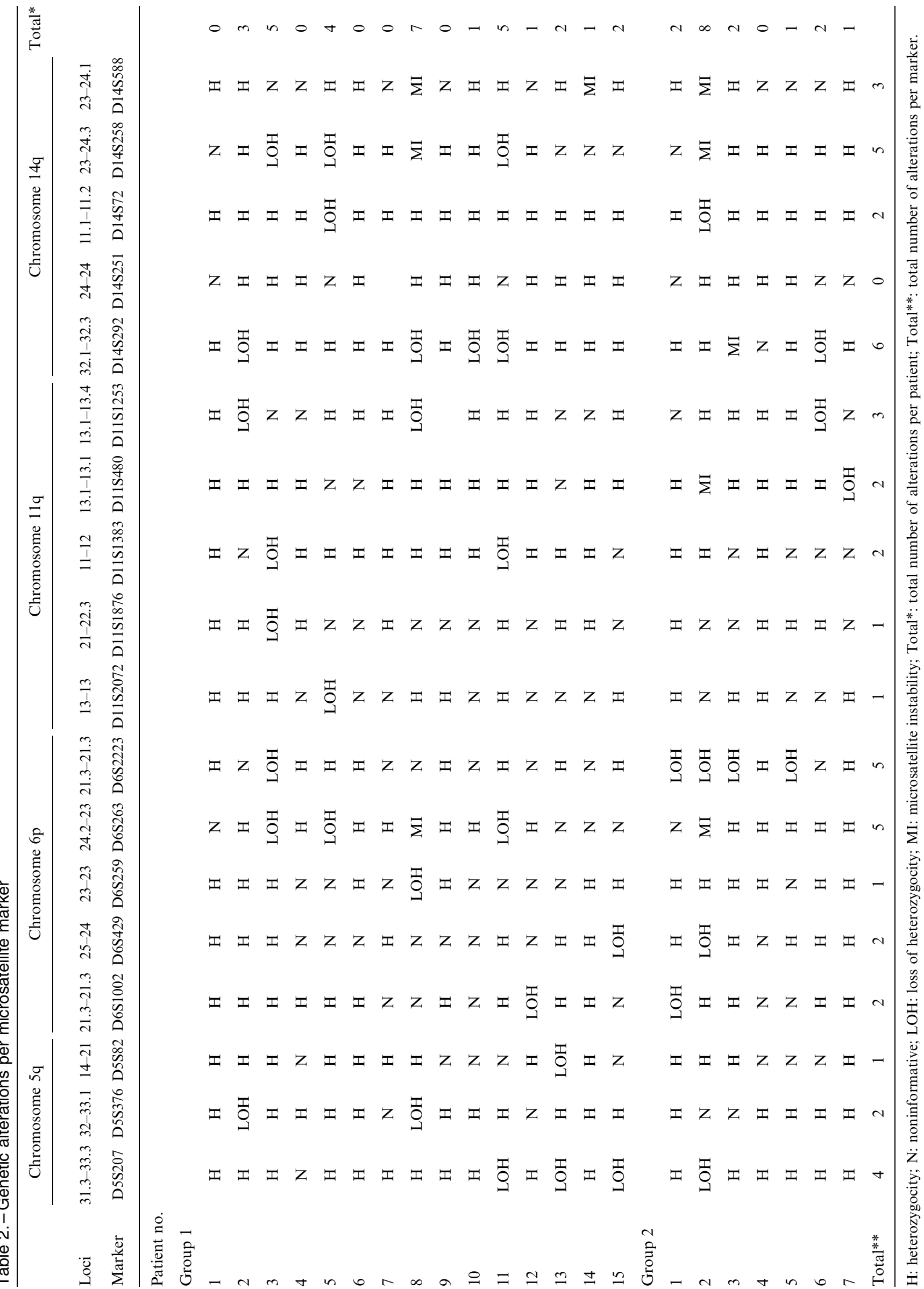



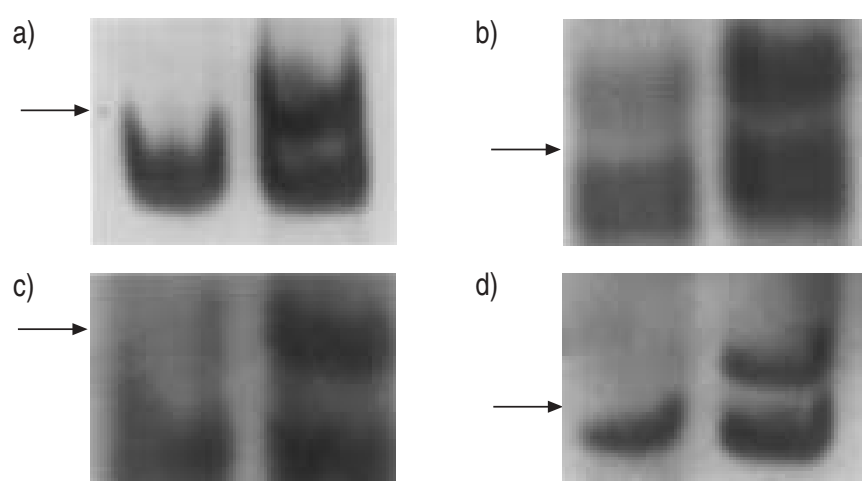

d)

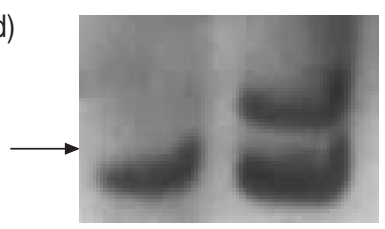

Fig. 1.- Typical examples of microsatellite instability (patient 14 (a)) and loss of heterozygocity (patients 3, 5, 16 (b, c and d, respectively)) of various markers. Left hand lane shows sputum cells and right hand lane shows blood cells.

each with five alterations (table 2). Finally, the most affected marker for MI was D14S588, which showed MI in three patients $(14 \%)$ (table 2). Asthmatic patients were divided into two groups, Group A, with few alterations (0-2 per patient) and Group B, with more alterations ( $\geqslant 3$ per person). Statistically significant differences were found in the mean IgE blood levels $\left(336.2 \pm 352.4 \mathrm{IU} \cdot \mathrm{mL}^{-1}\right.$ versus $165.1 \pm 146$ $\left.\mathrm{IU} \cdot \mathrm{mL}^{-1}\right)$ and eosinophil count $\left(560 \pm 385\right.$ cells $\cdot \mathrm{mL}^{-1}$ versus $256.8 \pm 200$ cells $\cdot \mathrm{mL}^{-1}$ ) between the two groups (fig. 2). Asthmatics of Group B showing higher levels of both IgE $(p<0.02)$ and eosinophils $(p<0.03)$ than Group A (fig. 2). No statistically significant difference was found in the spirometric values of the two groups.

\section{Discussion}

In the present study, genetic alterations in microsatellite DNA were studied in 22 patients with moderate asthma. The results showed that $73 \%$ of the asthmatic patients exhibited

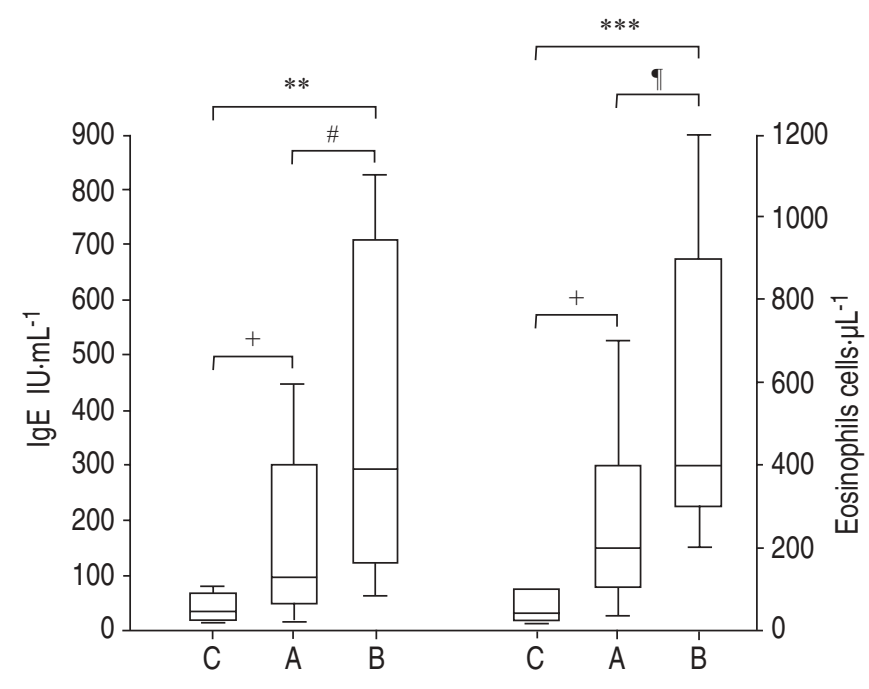

Fig. 2.-Serum immunoglobulin $\mathrm{E}$ (IgE) and blood eosinophils in Group A (asthmatics with less than three genetic alterations (A)), Group B (asthmatics with three or more genetic alterations (B)), and control subjects (C). The box extends from the 10-95th percentile with a line at the median. The whiskers extend above and below the box to show the highest and lowest values. $* *: \mathrm{p}=0.01 ; * * *: \mathrm{p}=0.001$; \#: $\mathrm{p}=0.02 ;{ }^{\uparrow}$ : $\mathrm{p}=0.03 ;{ }^{+}$: nonsignificant. genetic alterations, either MI or LOH, while none of the healthy subjects exhibited any alteration.

\section{Critique of the methods}

The small number of patients could be a limitation of this study. However, the frequency of alterations found was highly significant, even in this small cohort of patients. In addition, only six normal subjects were tested. However, previous studies by the authors in 116 normal subjects did not show any genetic alteration, either MI or LOH, when DNA of sputum cells were compared with that of blood cells, using a large variety of markers nonspecific for asthma [25-27].

Evidence of $\mathrm{LOH}$ was found in as many as $68 \%$ of the subjects with asthma in the present study, despite the benign nature of the disease [30]. The analysis of polymorphic markers for $\mathrm{LOH}$ is a common strategy for the identification of a putative suppressor gene in malignant or premalignant diseases. In malignancies, observation of $\mathrm{LOH}$ at a specific chromosomal marker in cells from the tumour suggests the presence of a closely linked tumour suppressor gene, the loss of which is involved in pathogenesis of the tumour.

$\mathrm{LOH}$ is a phenomenon that has also been detected in benign diseases characterised by hyperplasia or dysplasia of normal cells, such as actinic keratosis, pterygium, and atherosclerosis [20-24]. In actinic keratosis, thought to be a premalignant condition that gives rise to squamous cell carcinoma, the frequency of $\mathrm{LOH}$ is greater than that detected in skin cancer [21]. Nevertheless, the role of tumour suppressor genes in the homeostasis and proliferation of human cells is still not fully understood [31].

Although sputum contains a large number of degenerate cells in various stages of apoptosis, the fact that $\mathrm{LOH}$ or MI were not detected in the normal subjects in the current study and of previous studies [19, 25-27], support the hypothesis that these are disease specific findings.

The findings of a high frequency of $\mathrm{LOH}$ in chromosomal areas that harbour genes of cytokines and mediators with a controlling role in remodelling of the airways, bronchial hyperresponsiveness and atopy in the current study, support the hypothesis that those processes are significant in the development of asthma [5-15]. In particular, the authors found that the group of asthmatic patients that exhibited a high mutation rate showed a significantly higher blood $\mathrm{IgE}$ level and eosinophil count compared with the asthmatics with alterations in fewer than three markers and the controls (fig. 2). This high frequency of mutation detected in the genetic locus of genes controlling the inflammation and bronchial hyperresponsiveness associated with altered phenotypic elements of allergy and asthma (increased IgE and eosinophils) indicate that those loci may play a role in the pathogenesis of asthma. However, further studies are needed to clarify these findings. In addition, fine mapping with additional markers of the chromosomal regions investigated in this study is needed for a more detailed explanation of the role of $\mathrm{LOH}$ in these areas of the genome.

The microsatellite analysis revealed an additional genetic alteration in asthma, the MI that was found in $18 \%$ of the subjects. MI has been detected in almost all human tumours as well as in benign diseases, such as pterygium, idiopathic pulmonary fibrosis, sarcoidosis and COPD [16-27]. The precise significance of these findings is obscure because of the limited information on the genetic basis of the above diseases. However, the authors suggest that the relatively high mutation rate in asthma, as reflected in the instability of microsatellite sequences, indicates a destabilisation of the genome that may affect other genes and result in the deregulation of the cells 
harbouring these mutations. MI could be an early event in disease associated with DNA repair deficiency. Oxidative stress may be an important factor leading to DNA alteration.

If $\mathrm{MI}$ and/or $\mathrm{LOH}$ is indeed associated with the development of structural alterations in asthma, it may be involved in the induction of the increased mitotic rate of myofibroblasts, myocytes and fibroblasts that contribute to the remodelling of the airways. However, this hypothesis has to be tested. Finally, it could be of interest to identify the type of cell or cells that exhibit those genetic alterations, and to investigate if those phenomena are seen in asthmatics of other ethnicities (non-Greek). It must be stated that the findings of this study cannot be generalised to all severity groups or steroid naive patients.

In conclusion, the results of this study showed that both loss of heterozygosity and microsatellite instability are detectable phenomena in the sputum cells of asthmatic patients and that these alterations may play a role in the pathogenesis of the disease. Further studies are needed to clarify the significance of the loss of heterozygosity and microsatellite instability exhibited in regions of the genome that harbour candidate genes for asthma and encode important mediators of airway inflammation and remodelling.

\section{References}

1. Guidelines for the diagnosis and management of asthma. Expert panel report 2. NIH Publication No. 974051. Bethesda, MD, USA, NIH, 1997.

2. Beasley R, Roche WR, Roberts JA, Holgate ST. Cellular events in the bronchi in mild asthma and after bronchial provocation. Am Rev Respir Dis 1989; 139: 806-817.

3. Busse WW, Calhoun WF, Sedwick JD. Mechanisms of airway inflammation in asthma. Am Rev Respir Dis 1993; 147: Suppl. 6, 20-24.

4. Horwitz JR, Busse WW. Inflammation and asthma. Clin Chest Med 1995; 16: 583-602.

5. Bousquet J, Jeffery PK, Busse WW, Johnson M, Vignola AM. Asthma. From bronchoconstriction to airways inflammation and remodeling. Am J Respir Crit Care Med 2000; 161: 1720-1745.

6. Elias JA. Airway remodeling in asthma. Am J Respir Crit Care Med 2000; 161: Suppl. 3, 168-171.

7. Thomas NS, Wilkinson J, Holgate ST. The candidate region approach to the genetics of asthma and allergy. Am J Respir Crit Care Med 1997; 156: Suppl. 4, 144-151.

8. Sandford A, Weir T, Pare P. The genetics of asthma. Am J Respir Crit Care Med 1996; 153: 1749-1765.

9. Sandford A, Pare P. The genetics of asthma. Am J Respir Crit Care Med 2000; 161: Suppl. 3, 202-206.

10. Bleecker E, Postma D, Meyers D. Evidence for multiple genetic susceptibility loci for asthma. Am J Respir Crit Care Med 1997; 156: Suppl. 4, 113-116.

11. The collaborative study on the genetics of asthma. A genome-wide search for asthma susceptibility loci in ethnically diverse populations. Nat Genet 1997; 15: 389-392.

12. Rosenwasser L, Borish L. Genetics of atopy and asthma: the rationale behind promoter-based candidate gene studies (IL-4 and IL-10). Am J Respir Crit Care Med 1997; 156: Suppl. 4, 152-155.

13. Postma DS, Bleecker ER, Amelung PJ, et al. Genetic susceptibility to asthma - bronchial hyperresponsiveness coinherited with a major gene for atopy. $N$ Engl $J$ Med 1995; 333: 894-900.

14. Kips JC. Cytokines in asthma. Eur Respir J 2001; 18: Suppl. 1, 24-33.

15. Busse WW, Banks-Schlegel S, Wenzel ES. Pathophysiology of severe asthma. J Allergy Clin Immunol 2000; 106: 10331042.

16. Loeb LA. Microsatellite instability: marker of a mutator phenotype in cancer. Cancer Res 1994; 54: 5059-5063.

17. Field JK, Kiaris H, Howard P, Vaughan ED, Spandidos DA, Jones AS. Microsatellite instability in squamous cell carcinoma of the head and neck. Br J Cancer 1995; 75: 10651069.

18. Loeb LA, Christian FC. Multiple mutation in human cancers. Mutation Res 1996; 350: 279-286.

19. Froudarakis ME, Sourvinos G, Fournel P, et al. Microsatellite instability and loss of heterozygosity at chromosomes 9 and 17 in non-small cell lung cancer. Chest 1998; 113: 1091-1094.

20. Rehman I, Quinn AG, Healy E, Rees JL. High frequency of loss of heterozygosity in actinic keratosis, a usually benign disease. Lancet 1994; 344: 788-789.

21. Kushida Y, Miki H, Ohmori M. Loss of heterozygosity in actinic keratosis, squamous cell carcinoma and sun-exposed normal-appearing skin in Japanese: difference between Japanese and Caucasians. Cancer Letters 1999; 140: 169175.

22. Detorakis ET, Sourvinos G, Tsamparlakis J, Spandidos DA. Evaluation of loss of heterozygosity and microsatellite instability in human pterygium: clinical correlations. $\mathrm{Br} \mathrm{J}$ Ophthalmol 1998; 82: 1324-1328.

23. Spandidos DA, Sourvinos G, Kiaris H, Tsamparlakis J. Microsatellite instability and loss of heterozygosity in human pterygia. Br J Ophthalmol 1997; 81: 493-496.

24. Spandidos DA, Ergazaki M, Arvanitis D, Kiaris $H$. Microsatellite instability in human atherosclerotic plaques. Biochem Biophys Res Commun 1996; 220: 137-140.

25. Siafakas NM, Tzortzaki EG, Sourvinos G, et al. Microsatellite DNA instability in chronic obstructive pulmonary disease. A marker of genetic susceptibility? Chest 1999; 116 : 47-51.

26. Vassilakis DA, Sourvinos G, Markatos M, et al. Microsatellite DNA instability and loss of heterozygosity in pulmonary sarcoidosis. Am J Respir Crit Care Med 1999; 160: 1729-1733.

27. Vassilakis DA, Sourvinos G, Spandidos DA, Siafakas NM, Bouros D. Frequent genetic alterations at the microsatellite level in cytologic sputum samples of patients with idiopathic pulmonary fibrosis. Am J Respir Crit Care Med 2000; 162: $1115-1119$.

28. Grootendorst DC, Sont JK. Comparison of inflammatory cell counts in asthma: induced sputum vs. bronchoalveolar lavage and bronchial biopsies. Clin Exp Allergy 1997; 27: 769-779.

29. Kips JC, Peleman RA, Pauwels RA. Methods of examining induced sputum: do differences matter? Eur Respir J 1998; 11: $529-533$.

30. Mcduffie HH. Atopy and primary lung cancer. Chest 1991; 99: $404-407$.

31. Teh BT, Larsson C, Nordenskjold M. Tumor suppressor genes (TSG). Anticancer Res 1999; 19: 4715-4728. 